\title{
Detection of anti-cytokeratin 8 antibody in the serum of patients with cryptogenic fibrosing alveolitis and pulmonary fibrosis associated with collagen vascular disorders
}

Naomi Dobashi, Jiro Fujita, Yuji Ohtsuki, Ichiro Yamadori, Takeo Yoshinouchi,
Tadashi Kamei, Michiaki Tokuda, Satoko Hojo, Hiroki Okada, Jiro Takahara
First Department of Internal Medicine, Kagawa Medical University, 1750-1 Miki-cho, Kita-gun, Kagawa 761-0793, Japan

N Dobashi

J Fujita

M Tokuda

$S$ Hojo

H Okada

J Takahara

Department of Respiratory Medicine, Gamagohri City Hospital, Aichi, Japan $\mathrm{T}$ Yoshinouchi

Department of Internal Medicine, Kagawa Prefectural Central Hospital, Kagawa, Japan

T Kamei

Department of Pathology, Okayama University Medical School, Okayama,

Japan

I Yamadori

Department of Pathology, Kochi Medical School, Kochi, Japan

Y Ohtsuki

Correspondence to: Dr J Fujita.

Received 27 February 1998 Returned to authors 27 April 1998

Revised manuscript received 26 May 1998

Accepted for publication

15 June 1998

\begin{abstract}
Background-It has been suggested that the humoral immune system plays a role in the pathogenesis of cryptogenic fibrosing alveolitis (CFA). Although circulating autoantibodies to lung protein(s) have been suggested, none of the lung proteins have been characterised. The purpose of this study was to determine the antigen to which the serum from patients with pulmonary fibrosis reacted.

Methods-The anti-A549 cell antibody was characterised in a patient with CFA using Western immunoblotting and immunohistochemical staining of A549 cells. As we identified that one of the antibodies against A549 cells was anti-cytokeratin 8, the expression of $\mathrm{mRNA}$ of cytokeratin 8 in A549 cells was evaluated. In addition, we attempted to establish an enzyme linked immunosorbent assay to measure the levels of anti-cytokeratin 8 antibody in the serum of patients with CFA and pulmonary fibrosis associated with collagen vascular disorders (PF-CVD).
\end{abstract}

Results-Initially two anti-A549 cell antibodies were detected in the serum of patients with pulmonary fibrosis, one of which was characterised as anticytokeratin 8 antibody by Western immunoblotting. We were able to establish an ELISA to measure anti-cytokeratin 8 antibody and found significantly higher levels in patients with CFA and PF-CVD than in normal volunteers, patients with sarcoidosis, pneumonia, and pulmonary emphysema.

Conclusions-One of the anti-A549 cell antibodies in the serum of patients with CFA was against cytokeratin 8 . The serum levels of anti-cytokeratin 8 antibody were increased in patients with CFA and PFCVD. These results suggest that anticytokeratin 8 antibody may be involved in the process of lung injury in pulmonary fibrosis.

(Thorax 1998;53:969-974)

Keywords: A549 cell; antibody; cytokeratin 8; idiopathic pulmonary fibrosis; collagen vascular disorders

Cryptogenic fibrosing alveolitis (CFA) and pulmonary fibrosis associated with a collagen vascular disorder (PF-CVD) are inflammatory lung diseases of unknown aetiology that are characterised by the accumulation of neutrophils and mononuclear cells. ${ }^{12}$ Increased numbers of neutrophils, eosinophils, and CD4 positive lymphocytes as well as raised levels of immunoglobulin have been reported in the bronchoalveolar lavage fluid of patients with CFA. ${ }^{2}{ }^{4}$ This suggests an immunological pathogenesis for the disease although no definite aetiological factors have been indicated.

Wallace et al recently reported the presence of circulating autoantibodies in patients with CFA. ${ }^{5}{ }^{6}$ However, none of the target antigens have been characterised. We have therefore evaluated the autoantibody against A549 cells and have identified one of the antigens to be cytokeratin 8 .

\section{Methods}

SUBJECTS

Twenty one patients (11 women) of median age 68 years (range 44-86) with a diagnosis of pulmonary fibrosis were studied from 1990 to 1996. Of the 21 patients, 12 had IPF and nine had PF-CVD (four rheumatoid arthritis, four dermatomyositis, and one Sjogren syndrome). There were 13 non-smokers, two ex-smokers, and six current smokers. The diagnoses were made on clinical, radiological, physiological, and histological grounds. The criteria used included history of exertional dyspnoea and cough, fine crackles on physical examination, compatible findings on the chest radiograph (diffuse basal reticulonodular shadowing), physiological abnormalities of restrictive lung defects including decreased transfer factor, and abnormal $\mathrm{PaO}_{2}$ at rest and/or with exertion. Histological confirmation was obtained in all cases by open lung biopsy. Histological examination of all patients with PF-CVD showed a pattern of usual interstitial pneumonia (UIP). In all patients high resolution computed tomographic scanning of the lungs (HRCT) was performed. None of the patients received immunosuppressive treatment such as corticosteroids or cyclophosphamide. Lung function tests (\% vital capacity (VC) and forced expiratory volume in one second $\left(\mathrm{FEV}_{1}\right)$ ) were performed in all patients. We also studied 15 normal subjects (seven women) of median age 33 years, all of whom were non-smokers and, as a control for different pulmonary diseases, we studied five patients with sarcoidosis (four women) of median age 46 years, all nonsmokers, 16 with pneumonia (six women) of 


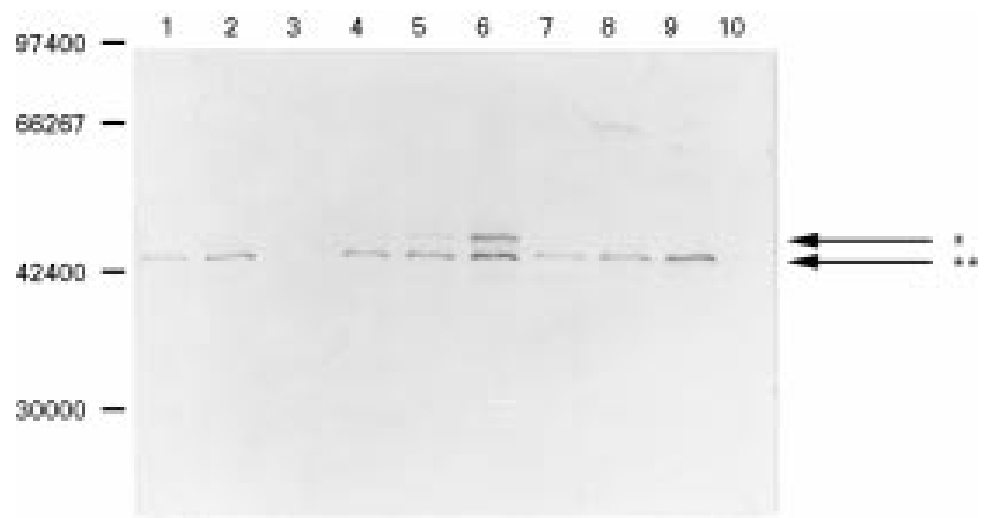

Figure 1 Western immunoblot analysis using serum from a patient against lysates of several cell lines. Lane 1, HL60; lane 2, K562; lane 3, U937; lane 4, Daudi; lane 5, PC9; lane 6, A549; lane 7, furkat; lane 8, TK130; lane 9, TO1019; lane 10, MN321. Although only a single band (arrow **) was detected in HL60, K562, Daudi, furkat, TK130, TO1019, and MN321, two bands (arrow * and ${ }^{\star *}$ ) were detected in PC9 and A549.

median age 65 years, six of whom were non-smokers and 10 were smokers, and 10 patients with pulmonary emphysema (all men) of median age 73 years, all of whom were smokers.

The protocols for this study were approved by the institutional review board for human studies and informed written consent was obtained from the subjects.

BLOOD SAMPLES

Peripheral venous blood samples with and without ethylene diamine tetra-acetic acid (EDTA) were obtained before breakfast. After centrifugation at $1000 \mathrm{~g}$ for 10 minutes at $4^{\circ} \mathrm{C}$ the serum was frozen and stored at $-70^{\circ} \mathrm{C}$ until used. Arterial blood oxygen and carbon dioxide tensions $\left(\mathrm{PaO}_{2}\right.$ and $\left.\mathrm{PaCO}_{2}\right)$ were measured with a blood gas analyser. To evaluate the antibodies against several cell lines the serum of a 66 year old female patient with CFA was used.

CELL LINES

The following cell lines were used: A549, PC9 (derived from adenocarcinoma of the lung), TK130, TO1019, MN321 (small cell carcinoma of the lung), HL60 (acute promyelocytic leukaemia), K562 (chronic myelogenous leukaemia), U937 (lymphoma), and Jurkat (leukaemia).

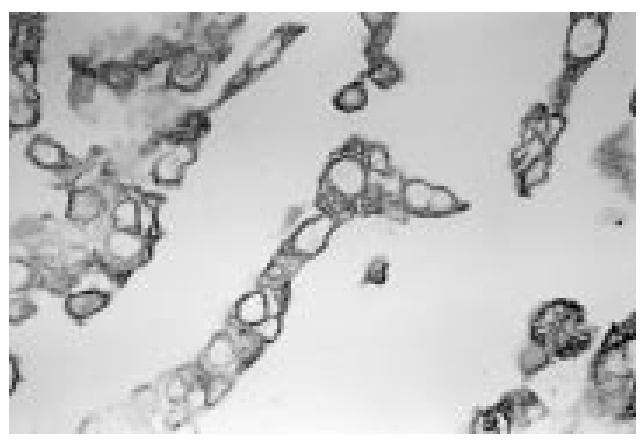

Figure 2 Immunohistochemical staining of A549 cells with anti-cytokeratin 8 monoclonal antibody. The cytoplasm of A549 cells was clearly and strongly stained. The nuclei were completely negative (avidin-biotin peroxidase complex method, $\times 580)$.
Table 1 Immunohistochemical staining of A549 cells by several monoclonal antibodies against cytokeratins

\begin{tabular}{llll}
\hline Antibodies & Cytokeratins & Results & $\begin{array}{l}\text { Molecular } \\
\text { weight }(k D)\end{array}$ \\
\hline 35ßH11 (MA902) & CK 8 & $(+)$ & 52.5 \\
CK18 & CK18 & $(+)$ & 45 \\
CAM5.2 & CK 8, CK 18 & $(+)$ & $52.5,45$ \\
CK14 & CK14 & $(-)$ & 50 \\
CK16 & CK16 & $(-)$ & 48 \\
CK17 & CK17 & $(-)$ & 46 \\
CK19 & CK19 & $(-)$ & 40 \\
\hline
\end{tabular}

SDS-PAGE ELECTROPHORESIS AND WESTERN BLOTTING

SDS-polyacrylamide gel electrophoresis was performed according to Laemmli's method ${ }^{7}$ with a slight modification. Lysates of cell lines were mixed with sodium dodecyl sulphate (SDS $2.0 \%)$ and heated $\left(100^{\circ} \mathrm{C}, 5 \mathrm{~min}\right)$. The samples were then applied to a $10 / 20 \%$ SDS polyacrylamide gel, electrophoresed $(60 \mathrm{~mA}$, $120 \mathrm{~min}$ ), fixed in 50\% methanol, $10 \%$ acetic acid, and stained with Coomassie Blue. Standard molecular weight markers purchased from Daiichi-Kagaku (Tokyo, Japan) comprised egg lysozyme (MW 14 400), trypsin inhibitor (MW 20 100), carbonic anhydrase (MW 30 000), aldolase (MW 42400 ), bovine albumin (MW 66 000), and phosphorylase B from rabbit muscle (MW 97 400). Commercially available purified keratin from human epidermis (Sigma Chemical Co, lot 95H11291, St Louis, Missouri, USA) and recombinant human cytokeratin 8 (Progen Biotechnik GmbH, lot 503209, Heidelberg, Germany) were also used as the positive control.

Proteins were electrophoretically transferred onto nitrocellulose membrane ${ }^{8}$ and were detected by immunoblotting using the serum from one patient, peroxidase conjugated goat anti-human IgG antibody (Sigma ImmunoChemicals, lot 094H-4810, St Louis, Missouri, USA), and stained with 4CN PLUS for chromogenic detection of horse radish peroxidase (NEM Life Science Products, Boston, Massachusetts, USA). Western immunoblots for cytokeratin 8 were also performed using a mouse monoclonal anti-human cytokeratin antibody (CAM5.2, lot 61217, Becton Dickinson Immunocytometry Systems, San Jose, California, USA) which detects human cytokeratin 8 and cytokeratin 18, and gold conjugated anti-mouse IgG antibody (Sigma Chemical Co, lot 98F8882). Silver staining was then performed using Immuno-Blot gold enhancement kit (Bio-RAD Laboratories, Hercules, California, USA). We also evaluated peroxidase conjugated goat anti-human IgA (Sigma ImmunoChemicals, lot 023H-8868) and anti-human IgM (Sigma ImmunoChemicals, lot 094H-8832) as second antibodies.

IMMUNOHISTOCHEMISTRY OF A549 CELLS BY SEVERAL ANTICYTOKERATIN ANTIBODIES

To evaluate the expression of several cytokeratins in A549 cells, immunohistochemical staining by anti-human monoclonal antibodies against several cytokeratins was performed. A549 cells were immunohistochemically stained, employing the avidin-biotin peroxi- 

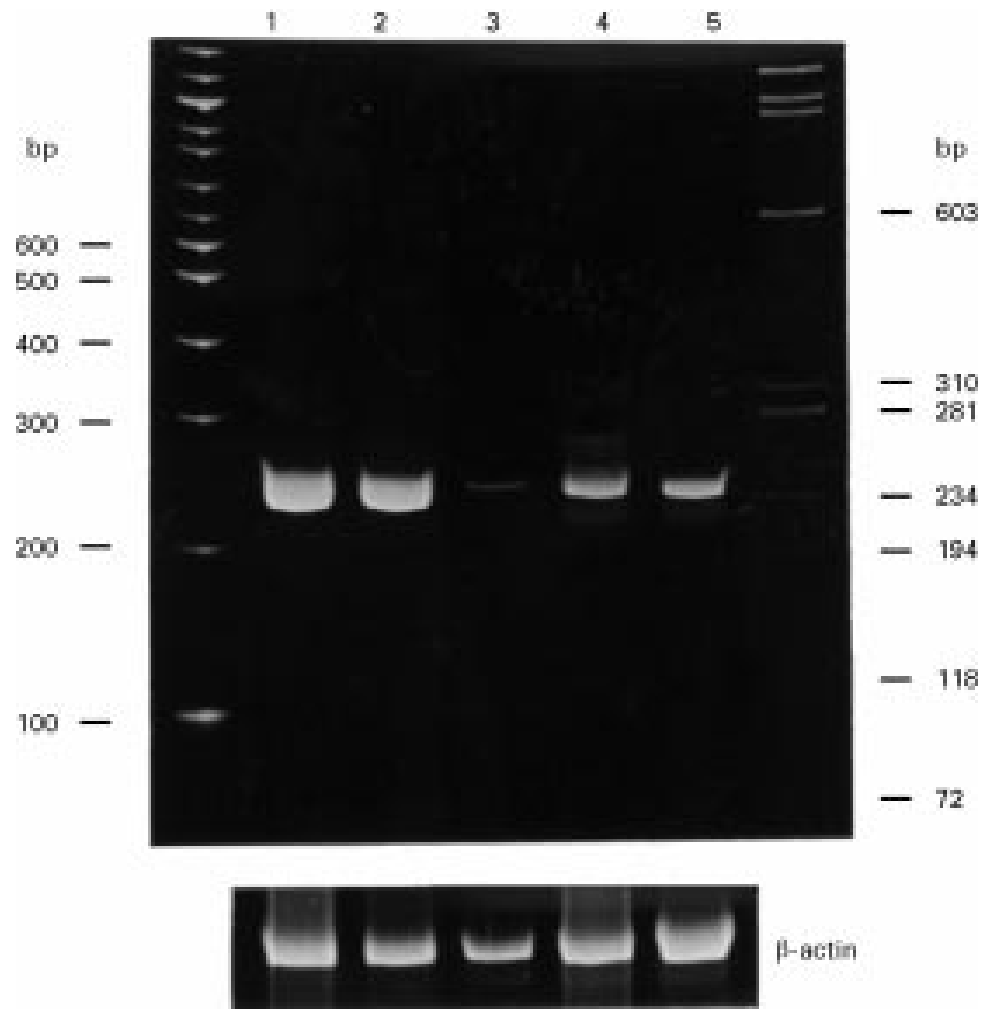

Figure 3 Expression of cytokeratin 8 and $\beta$-actin $m R N A$ in several lung cancer cell lines by the RT-PCR method. Lane 1, PC9 (adenocarcinoma); lane 2, A549 (adenocarcinoma); lane 3, TK130 (small cell lung cancer); lane 4, TO1019 (small cell lung cancer); lane 5, MN321 (small cell lung cancer). DNA ladder (100 bp) and X174 Hae III digest were used as DNA size markers. Although all cell lines expressed $m R N A$ for cytokeratin 8 (approximately 244 bp), A549 and PC9 expressed increased amounts of $m R N A$.

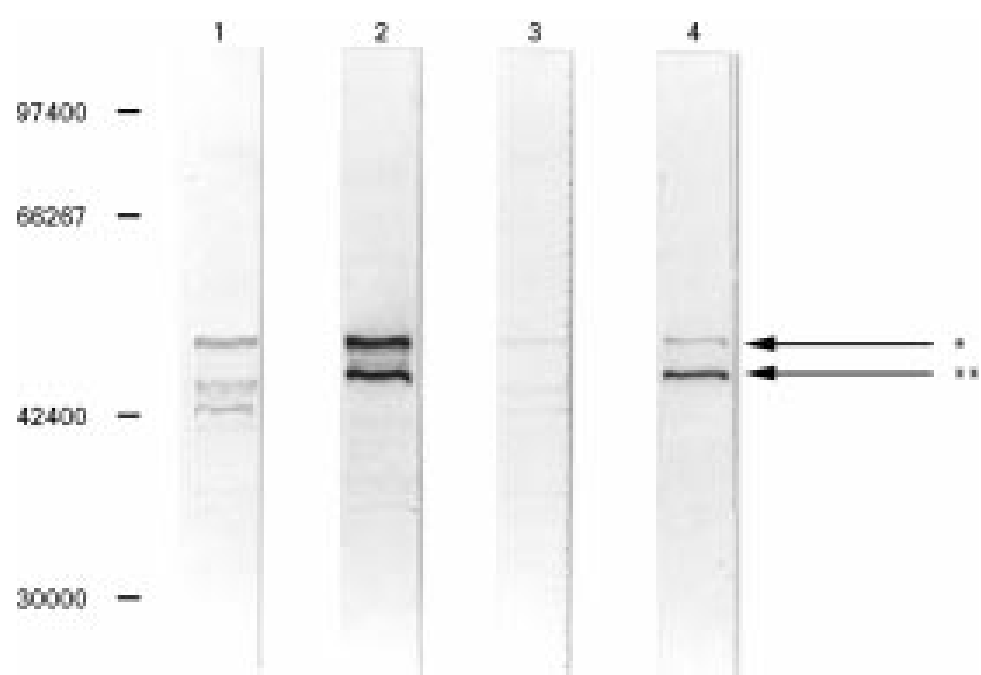

Figure 4 Western immunoblot analysis using the anti-human cytokeratin antibody CAM5. 2 which detects cytokeratin 8 and cytokeratin 18 and patient's serum. Lane 1 , CAM5.2 antibody against A549; lane 2, patient's serum against A549; lane 3, CAM5.2 antibody against PC9; lane 4,patient's serum against PC9. The positive band with a higher molecular weight (arrow ${ }^{\star}$ ) corresponded to cytokeratin 8. The positive band with a lower molecular weight was not stained by CAM5.2 antibody, suggesting that this band was not cytokeratin 18

dase complex method (Dako LSAB kitperoxidase, Dako Corp, Kyoto, Japan) using mouse monoclonal antibodies to cytokeratins. The monoclonal antibodies used were as follows: 35 $\beta$ H11 (MA902) which detects cytokeratin 8 (Enzo Diagnostics Inc, New York, USA, 1:5000 dilution), anti-human cytokeratins 18 and 19 (ScyTek Lab, Logan, Utah, USA, each 1:30 dilution), CAM5.2 which detects both cytokeratin 8 and 18 (Becton Dickinson Immunocytometry Systems, San Jose, California, USA, 1:20 dilution), antihuman cytokeratins 14, 16 and 17 (Novo Castra Lab Ltd, Newcastle upon Tyne, UK, 1:20, $1: 30$ and 1:30 dilution, respectively). In order to retrieve and increase the immunoreactivities, cytokeratins 14, 17, 18, CAM5.2 and MA902 were preincubated with $0.1 \%$ pronase at $37^{\circ} \mathrm{C}$ for 20 minutes. Cytokeratins 16 and 19 were autoclaved at $132^{\circ} \mathrm{C}$ for 12 minutes.

EXPRESSION OF MRNA FOR CYTOKERATIN 8 IN A549 CELLS BY RT-PCR

To confirm the expression of cytokeratin 8 mRNA from A549 cells, reverse transcriptasepolymerase chain reaction (RT-PCR) was performed. Total RNA from each cell line was isolated by a single step acid guanidium-phenol chloroform extraction. Total RNA $(1 \mu \mathrm{g})$ was reverse transcribed into cDNA using random primers (Takara Shuzo Co, Kyoto, Japan) and avian myeloblastosis virus reverse transcriptase (Life Science Inc, Petersburg, Florida, USA) in a final volume of $20 \mu \mathrm{l}$. The cDNA was amplified by PCR. The primer sequences for cytokeratin 8 were as follows: sense primer AACAACCTTAGGCGGCAGCT, antisense primer GCCTGAGGAAGTTGATCTCG. PCR beads (Ready-To-Go, Amersham Pharmacia Biotech Ltd, Uppsala, Sweden) containing $50 \mathrm{pmol}$ of each primer, $1 \mu \mathrm{l}$ of cDNA, and $22 \mu \mathrm{l}$ of water were used. Thirty cycles were performed consisting of a 60 second denaturation at $95^{\circ} \mathrm{C}$ and annealing and polymerase extension for two minutes at $72^{\circ} \mathrm{C}$. All PCRs were terminated with a 10 minute extension at $72^{\circ} \mathrm{C}$. Ten $\mu \mathrm{l}$ aliquots of the PCR products were electrophoresed on $10 / 20 \%$ SDS polyacrylamide gel and analysed by direct visualisation after ethidium bromide staining. The expected size of the amplified fragment was 244 nucleotides.

ENZYME-LINKED IMMUNOSORBENT ASSAY FOR ANTI-CYTOKERATIN 8 AUTOANTIBODY IN HUMAN SERUM

An enzyme-linked immunosorbent assay (ELISA) was established to measure anticytokeratin 8 antibody levels in human serum samples. Serum was added to wells coated with recombinant human cytokeratin $8(0.5,1,2$, and $4 \mu \mathrm{g} / \mathrm{ml}$ ). After incubation and washing, the solid phase bound anti-human cytokeratin 8 autoantibody was further incubated with peroxidase conjugated goat anti-human IgG antibody (Sigma ImmunoChemicals, lot 094H-4810, diluted 1:1000). After further washes TMB Peroxidase EIA Substrate Kit (Bio-RAD Laboratories, Hercules, California, USA) was used to measure the amount of solid phase bound antibodies. The assay was calibrated using a standard solution of the patient's serum in which the anti-cytokeratin 8 antibody had been determined by Western immunoblotting. Data were expressed as mean values from duplicate determinations. 


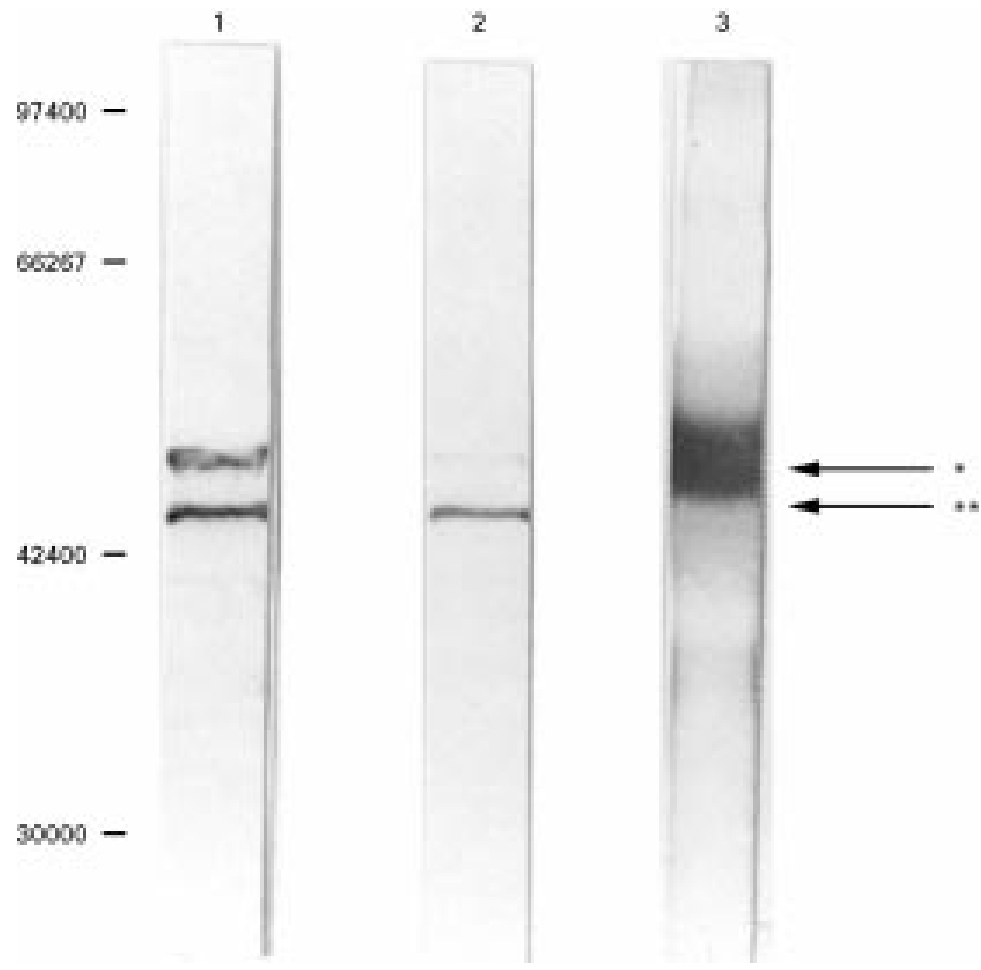

Figure 5 Western immunoblot analysis using the patient's serum against A549 (lane 1), PC9 (lane 2), and keratin from human epidermis (lane 3). The patient's serum strongly reacted with the keratin from human epidermis (arrow *). The positive band with a lower molecular weight (arrow ${ }^{\star}$ ) did not correspond to the keratin from human epidermis.

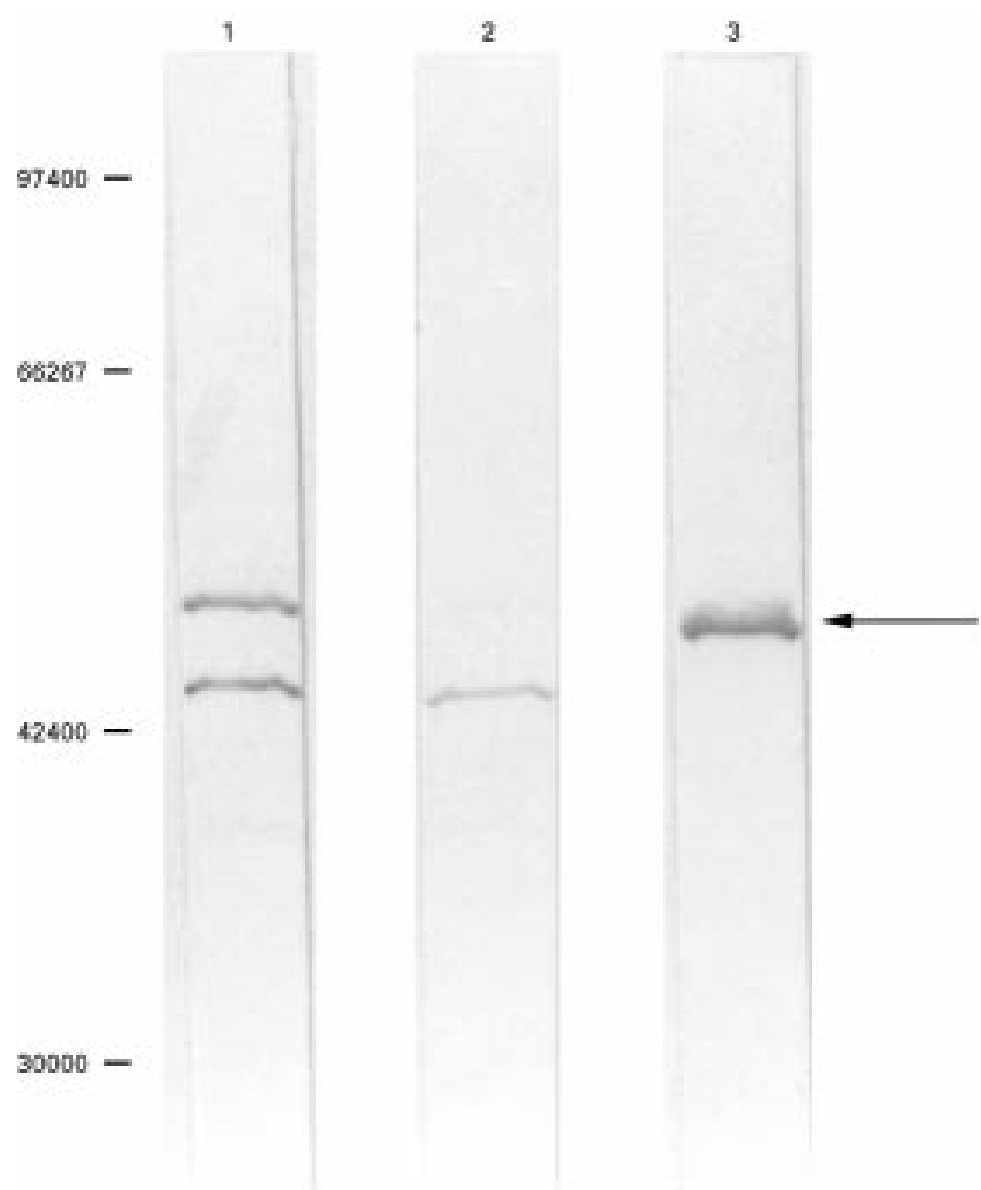

Figure 6 Western immunoblot analysis using the patient's serum against A549 (lane 1), PC9 (lane 2), and recombinant human cytokeratin 8 (lane 3). The patient's serum reacted strongly only with recombinant human cytokeratin 8.

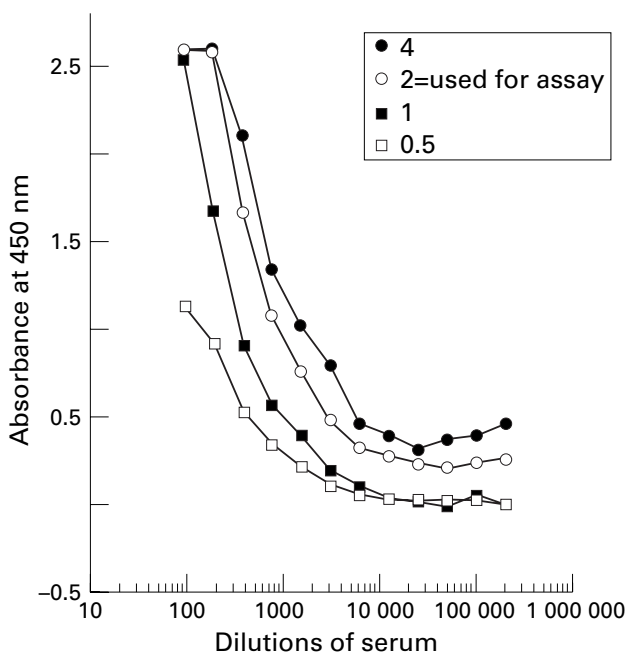

Figure 7 Standard curves of ELISA revealing anti-cytokeratin 8 antibody in patient's serum. Numbers represent concentrations of recombinant cytokeratin $8(\mu \mathrm{g} / \mathrm{ml})$ to coat wells.

\section{STATISTICAL METHODS}

The results were expressed as mean (SE) values. Comparisons of values between groups were analysed with the Mann-Whitney U test, a $p$ value of less than 0.05 being considered as significant.

\section{Results}

Figure 1 shows the Western immunoblot analysis of one patient's serum against lysates of several cell lines. Although only one band (MW 45 000) was detected in HL60 cells, K562 cells, Daudi cells, Jurkat cells, TK130, and TO1019, two bands (MW 52000 and 45 000) were found in PC9 and A549 cells. There were no positive reactions when antihuman $\operatorname{IgA}$ and $\operatorname{IgM}$ antibodies were used (data not shown).

Immunohistochemical staining of A549 cells with anti-cytokeratin 8 monoclonal antibody was restricted to the cytoplasm, and the nuclei were completely negative (fig 2 ). Table 1 summarises the results of immunohistochemical staining of A549 cells. The cytoplasm of A549 cells was also stained with anti-cytokeratin 18 monoclonal antibody. However, A549 cells were negative with anti-cytokeratin 14,16 , and 17 monoclonal antibodies. There were a few positive cells in the cytoplasm with anticytokeratin 19 antibody.

Figure 3 shows the expression of cytokeratin 8 mRNA in several lung cancer cell lines by RT-PCR. Although all cell lines expressed mRNA for cytokeratin 8, A549 and PC9 cells expressed increased amounts of mRNA.

Western immunoblot analysis using a patient's serum and anti-human cytokeratin (CAM5.2) which detects cytokeratin 8 and cytokeratin 18 against A549 cells and PC9 cells showed that the patient's serum and antihuman cytokeratin reacted with A549 cells and PC9 cells (fig 4). The positive band which had a higher molecular weight (approximately 52000 ) corresponded to cytokeratin 8. Western immunoblot analysis using a patient's serum against A549 cells, PC9 cells, and human keratin showed that the patient's serum 


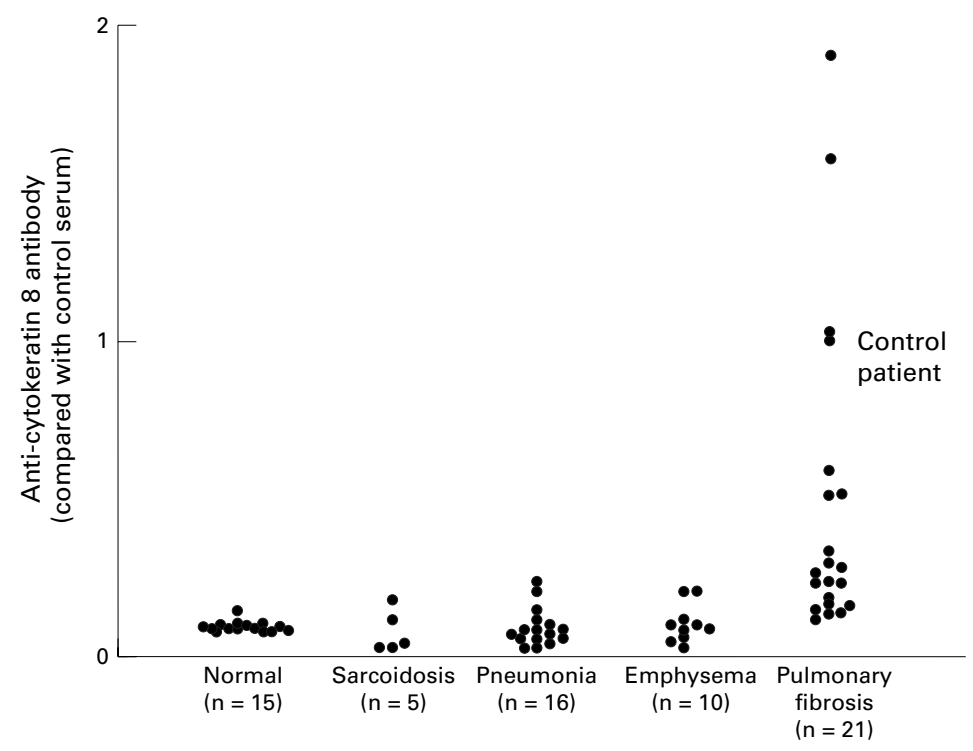

Figure 8 Levels of anti-human cytokeratin 8 antibodies in serum samples from patients and from normal volunteers. Mean (SE) levels of anti-human cytokeratin antibodies in the serum of patients with pulmonary fibrosis $(0.48(0.10))$ were significantly higher than those of normal volunteers $(0.1$ (0.004), $p<0.001$, Mann-Whitney $U$ test $)$ and of patients with sarcoidosis $(0.08(0.03), p<0.01)$, pneumonia $(0.09(0.02), p<0.001)$, and pulmonary emphysema $(0.11(0.02), p<0.001)$.

reacted strongly with the human keratin (fig 5). Western immunoblot analysis using a patient's serum against A549 cells, PC9 cells, and recombinant human cytokeratin 8 showed that the patient's serum reacted strongly with recombinant human cytokeratin 8 (fig 6).

Figure 7 shows standard curves of ELISA which detect anti-cytokeratin antibody in the patient's serum. Using this ELISA it was possible to measure the anti-human cytokeratin antibody in the patients' serum samples. Mean (SE) levels of anti-human cytokeratin antibodies in serum from patients with pulmonary fibrosis $(0.48(0.10)$ compared with the control patient's serum which was determined to 1.0 ) were significantly higher than those of normal volunteers (0.1 (0.004), p<0.001; fig 8). In addition, levels of anti-human cytokeratin antibodies in serum samples from patients with pulmonary fibrosis were significantly higher than those in patients with sarcoidosis $(0.08$ (0.03), p<0.01), pneumonia (0.09 (0.02), $\mathrm{p}<0.001)$, and pulmonary emphysema $(0.11$ (0.02), $\mathrm{p}<0.001)$. In patients with pulmonary fibrosis there was no significant difference between levels of anti-human cytokeratin antibodies in the serum of eight smokers (six current smokers and two ex-smokers, 0.404 $(0.102))$ and 13 non-smokers $(0.524(0.164))$.

\section{Discussion}

In this study we have demonstrated that one of the antibodies against A549 cells in patients with CFA and PF-CVD is anti-cytokeratin 8 antibody. Measurement of this antibody by ELISA showed that the levels in serum from patients with CFA and PF-CVD were significantly higher than levels in serum from normal volunteers and patients with other pulmonary diseases.

The current consensus is that, whatever the aetiological agent(s), CFA represents a persistent immunological reaction in the lung which results in scar formation. ${ }^{9}$ Data from bronchoalveolar lavage have shown increased numbers of neutrophils, eosinophils, and CD4 positive lymphocytes $^{3}$ as well as raised levels of immunoglobulin ${ }^{4}$ in the bronchoalveolar lavage (BAL) fluid of patients with CFA. In addition, there is evidence of a more general immune dysregulation with hypergammmaglobulinaemia, ${ }^{3}$ circulating immune complexes, ${ }^{10} 11$ and the production of recognised non-organ specific autoantibodies such as antinuclear factor and rheumatoid factor. ${ }^{12}$ Clinical studies have shown that collagen vascular disorders, which have a known immunological pathogenesis, are associated with an identical pattern of alveolitis, ${ }^{13}$ and it has also been reported that there may be large numbers of B lymphocytes and plasma cells in the lungs of patients with CFA. ${ }^{14}$ Furthermore, it has been reported that the B cell growth factor activity $^{15}$ and immunoglobulin ${ }^{4}$ in BAL fluid increases in patients with CFA compared with normal controls.

The presence of autoantibodies in patients with CFA has been implied and subsequently investigated. ${ }^{561216}$ The nature and location of the antigen(s) are believed to be associated with pulmonary epithelial lining cells and, perhaps, with capillary endothelial cells on the basis of ultrastructural studies ${ }^{17}$ and a previous demonstration of immune complexes at these sites. ${ }^{18}$

It has been reported that the serum from patients with CFA is positive on cryostat sections of lung tissues by an indirect immunofluorescence technique. ${ }^{16}$ Other investigators using ELISA techniques have found antibodies to the nuclear antigen topoisomerase II (170 $\mathrm{kD}$ ) in $38 \%$ of patients ${ }^{19}$ and hepatitis $\mathrm{C}$ virus in $28 \%$ of patients. ${ }^{20}$ Wallace et al have reported that circulating IgG autoantibodies to $70-90 \mathrm{kD}$ protein(s) which are associated with alveolar epithelial lining cells are detected in serum from patients with CFA. ${ }^{56}$ These findings suggest that there are several pulmonary autoantigens to which autoantibodies in the serum react.

We have shown that anti-cytokeratin 8 antibodies are present in serum samples from patients with CFA and PF-CVD. Cytokeratin is antigenically related to keratin and $\alpha$-helical coiled-coil protein. ${ }^{21}$ Some studies have shown that antibodies can penetrate cells in vivo. ${ }^{22-25}$ Antibodies that bind to cytokeratin 8 may therefore be pathologically significant. Defects in cytoskeletal organisation are known to be capable of disrupting cell function ${ }^{26}$ and may be characteristic of some pathological processes. ${ }^{27}$ It has been reported that antibodies to cytoskeletal proteins are associated with some organspecific autoimmune diseases. ${ }^{21}$ Cytokeratinspecific antibodies appear to increase in diseases such as alcoholic liver disease and rheumatic disorders, ${ }^{28}{ }^{29}$ and it has been suggested that anticytokeratin antibodies are formed in response to epithelial cell injury or death. ${ }^{30-33}$ However, none of these reports has described the autoantibody as specific to cytokeratin 8 .

Few studies have evaluated the clinical significance of anti-cytokeratin 8 autoantibody in serum. ${ }^{30}$ There appears to be a high incidence of antibodies against cytoskeletal proteins in normal serum which suggests that these antibodies 
may be a part of the natural/physiological autoantibody repertoire. ${ }^{30}$ However, since physiological autoantibodies are usually $\operatorname{IgM},{ }^{34}{ }^{35}$ the existence of the $\operatorname{IgG}$ type anti-cytokeratin 8 antibody in the serum may have been pathogenetically relevant to pulmonary fibrosis.

The significance of anti-cytokeratin 8 autoantibody in the pathogenesis of CFA and PF-CVD should be discussed. In the lung cytokeratin 8 is expressed in bronchoepithelial cells. ${ }^{36}$ Cytokeratin 8 may have been released from epithelial cells following cell injury. The resulting antibody-antigen interaction with immune complex formation could have a significant role in the perpetuation of the disease process, either by direct injury of epithelial cells or via local macrophage activation as they are cleared by phagocytosis.

In addition, it has been shown that wild type p53 is overexpressed in regenerated bronchoepithelial cells in patients with CFA. ${ }^{37}{ }^{38}$ It has also been reported that the expression of the human cytokeratin 8 gene is regulated by the p53 gene. $^{39}$ It is therefore possible that regenerated bronchoepithelial cells that had overexpressed p53 protein might have been selectively destroyed by anti-cytokeratin 8 antibody. However, we cannot rule out the possibility that the existence of cytokeratin 8 autoantibody is a non-specific consequence of lung injury. The significance of anticytokeratin 8 antibody in terms of disease severity, stage, prognosis, and possible response to treatment should therefore be evaluated in future studies.

In this study the serum of patients with CFA reacted strongly with two antigens of molecular weights 52000 and 45000 . Although we could characterise one protein with a molecular weight of 52000 as cytokeratin 8 , the other antigen still needs to be identified.

In conclusion, our results have shown that one of the anti-A549 cell antibodies in the serum of patients with CFA was anti-cytokeratin 8. In addition, levels of anti-cytokeratin 8 antibodies in the serum increased in patients with pulmonary fibrosis including PF-CVD. These results suggest that anti-cytokeratin 8 antibodies may play a significant role in the process of lung injury in pulmonary fibrosis.

1 Crystal RG, Bitterman PB, Rennard SI, et al. Interstitial lung diseases of unknown cause. Disorders characterized by chronic inflammation of the lower respiratory tract. $N$ Engl f Med 1984;310:154-66.

2 Peterson MW, Monick M, Hunninghake GW. Prognostic role of eosinophils in pulmonary fibrosis. Chest 1987;92: role of

3 Cherniack RM. Bronchoalveolar lavage constituents in healthy individuals, interstitial pulmonary fibrosis and selected comparison groups. Am Rev Respir Dis 1990; 141(Suppl):S169-93

4 Reynolds HY, Fulmer JD, Kazamierowski JA, et al. Analysis of cellular and protein content of bronchoalveolar lavage fluid from patients with idiopathic pulmonary fibrosis and chronic hypersensitivity pneumonitis. $\mathcal{F}$ Clin Invest 1977;59 165-75.

5 Wallace WAH, Roberts SN, Caldwell $\mathrm{H}$, et al. Circulating antibodies to lung protein(s) in patients with cryptogenic fibrosing alveolitis. Thorax 1994;49:218-24.

6 Wallace WAH, Schofiels JA, Lamb D, et al. Localization of a pulmonary autoantigen in cryptogenic fibrosing alveolitis. Thorax 1994;49:1139-45.

7 Laemmli UK. Cleavage of structural proteins during the assembly of the head of bacteriophage T4. Nature 1970;227:680.

8 Towbin H, Staehelin T, Gordon J. Electrophoretic transfer of proteins from polyacrylamide gels to nitrocellulose sheets. Proc Nat Acad Sci USA 1979;76:4350-4.
9 Kradin RL, Divertie MB, Colvin RB, et al. Usual interstitial pneumonitis is a $\mathrm{T}$ cell alveolitis. Clin Immunol Immunopneumonitis is a $\mathrm{T}$ cell

10 Haslam PL, Thomson B, Mohammed I, et al. Circulating immune complexes in patients with cyptogenic fibrosing alveolitis. Clin Exp Immunol 1979;37:381-90

11 Dreisen RB, Schwarz MI, Theofilopoulos AN, et al. Circulating immune complexes in the idiopathic interstitial pneumonias. N Engl $\mathcal{F}$ Med 1978;298:353-7.

12 Turner- Warwick $M$, Doniach D. Auto-antibodies in idiopathic pulmonary fibrosis. BMf 1965;1:886-91.

13 Wallaert B. Subclinical alveolitis in immunologic systemic disorders. Lung 1990;168(Suppl):974-83.

14 Haslam PL. Evaluation of alveolitis by studies of lung biopsies. Lung 1990;168(Suppl):984-92.

15 Emura M, Nagi S, Takeuchi M, et al. In vitro production of $\mathrm{B}$ cell growth factors and $\mathrm{B}$ cell differentiation factors by peripheral blood mononuclear cells and bronchoalveolar lavage T lymphocytes from patients with idiopathic pulmonary fibrosis. Clin Exp Immunol 1990;82:133-9.

16 Ehringer R. Similar frequency of auto-antibodies against type II pneumocytes and Clara cells in patients with interstitial lung disease and healthy persons. Klin Wochenshr 1991;69:297-302.

17 Corrin B, Dewar A, Rodriguez-Roisin R, et al. Fine structural changes in cryptogenic fibrosing alveolitis and asbestosis. F Pathol 1985;147:107-19.

18 Schwartz MI, Dreisen RB, Pratt DS, et al. Immunofluorescent pattern in idiopathic interstitial pneumonia. $\mathcal{F}$ Lab Clin Med 1978:91:929-35.

19 Meliconi R, Bestagno M, Sturani C, et al. Autoantibodies to DNA topoisomerase II in cryptogenic fibrosing alveolitis and connective tissue diseases. Clin Exp Immunol 1989;76:184-9.

20 Ohta K, Watanabe J, Hirai K, et al. High prevalence serum antibodies to hepatitis $\mathrm{C}$ virus in idiopathic pulmonary fibrosis. Am Rev Respir Dis 1992;145:A218.

21 Kurki P, Virtanen I. The detection of human antibodies against cytoskeletal components. F Immunol Methods 1984; 67:209-23.

22 Alarcon-Segovia D, Ruiz-Arguelles A, Fishbein E. Antibody to nuclear ribonucleoprotein penetrates live human mononuclear cells through Fc receptors. Nature 1978;271:67-9.

23 Alarcon-Segovia D, Ruiz-Arguelles A, Fishbein E. Antibody penetration into living cells. I. Intranuclear immunoglobulin in peripheral blood mononuclear cells in mixed connective tissue disease and systemic lupus erythemotosus. Clin Exp Immunol 1979;35:364-75.

24 Alarcon-Segovia D, Ruiz-Arguelles A, Fishbein E. Antibody penetration into living cells. II. antiribonucleoprotein IgG penetrates into Tc lymphocytes causing their deletion and the abrogation of suppresser function. F Immunol 1979;122: $1855-62$.

25 Alarcon-Segovia D. Penetration of antinuclear antibodies into immunoregulatory $\mathrm{T}$ cells: pathogenetic role in the connective tissue diseases. Clin Immmunol Allergy 1981;1: $117-26$.

26 Sturgess JM, Chao J, Turner JAP. Transposition of ciliary microtubules: another cause of impaired ciliary motility. $N$ Engl f Med 1980;303:318-22

27 Runger-Brandle E, Gabbiani G. The role of cytoskeletal and cytocontractile element in pathologic processes. Am $\mathcal{f}$ Pathol 1983;110:361-92.

28 Kurki P, Miettinen A, Salaspuro M, et al. Cytoskeleton antibodies in chronic active hepatitis, primary biliary cirrhosis, and alcoholic liver disease. Hepatology 1983;3:297-302.

29 Kurki P, Helve T, Virtanen I. Antibodies to cytoplasmic intermediate filaments in rheumatic diseases. $\mathcal{F}$ Rheumatol 1983;10:558-62.

30 Kurki P, Virtanen I. The detection of human antibodies against cytoskeletal components. F Immunol Methods 1984;

31 Zauli D, Crespi C, Dall'amore P, et al. Antibodies to the cytoskeleton components and other autoantibodies in inflammatory bowel disease. Digestion 1985;32:140-4

32 Grubauer G, Romani N Kofler H, et al. Apototic keratin bodies as autoantigen causing the production of IgM-antikeratin intermediate filament autoantibodies. F Invest Dermatol 1986;87:466-71.

33 Hintner H, Romani N, Stanzl U, et al. Phagocytosis of keratin filament aggregates following opsonization with IgGanti-keratin filament autoantibodies. F Invest Dermatol 1987;88:176-82.

34 Tron F, Le Guern C, Cazenave PA, Bach JF. Intrastain recurrent idiotypes among anti-DNA antibodies of (NZB $\times$

35 Tron F, Jacob L, Bach JF. Murine monoclonal anti-DNA antibodies with an absolute specificity for DNA have a large amount of idiotype diversity. Proc Nat Acad Sci USA 1983;80:6024-7.

36 Iyonaga K, Miyafuji M, Suga M, et al. Alterations in cytokeratin expression by the alveolar lining epithelial cells in lung tissue from patients with idiopathic pulmonary fibrosis. F Pathol 1997;182:217-24.

37 Kuwano K, Kunitake R, Kawasaki M, et al. p21Waf1/Cip1/ Sdi1 and p53 expression in association with DNA strand breaks in idiopathic pulmonary fibrosis. Am F Respir Crit Care Med 1996;154:477-83.

38 Hojo S, Fujita J, Yamadori I, et al. Overexpression of p53 protein in interstitial lung diseases. Respir Med 1998;92. $184-90$.

39 Mukhopadhyay T, Roth JA. p53 involvement in activation of the cytokeratin 8 gene in tumor cell lines. Anticancer Res 1996;16:105-12. 